

\section{Sumário}

EDITORIAL

Bruno Amaral Machado, Camilla de Magalhães Gomes e Soraia Mendes

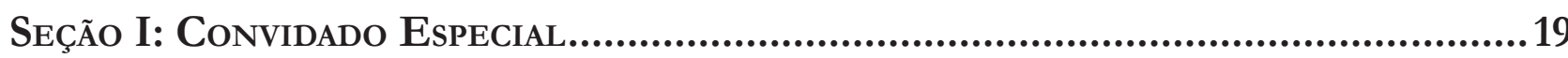

Autonomia Pessoal, Destino, julgamentos e instituições no Brasil: Notas Sobre uma PERGUNTA E ALGUMAS RESPOSTAS

Luiz Edson Fachin

SEÇÃo 2: Dossiê Temático....................................................................................40

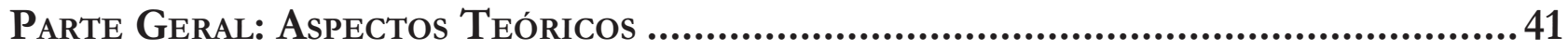

Raça e essencialismo na Teoria Feminista do Direito .......................................................43

Angela P. Harris, Tradução de Camilla de Magalhães Gomes e Ísis Aparecida Conceição

Políticas da morte: Covid-19 E Os Labirintos da Cidade Negra ........................................75

Ana Flauzina e Thula Pires

QUem PARIU AMÉFrica?: TRABALHO DOMÉSTICO, CONSTITUCIONALISMO E MEMÓRIA EM PRETUGUÊS

Juliana Araújo Lopes

O Lixo Vai Falar: Racismo, Sexismo e Invisibilidades do Sujeito Negro nas Narrativas de Direitos Humanos

Ciani Sueli das Neves

DiREITOS HUMANOS, DECOLONIALIDADE E FEMINISMO DECOLONIAL: FERRAMENTAS TEÓRICAS PARA A COMPREENSÃO DE RAÇA E GÊNERO NOS LOCAIS DE SUBALTERNIDADE

Rute Passos, Letícia Rocha Santos e Fran Espinoza

Direito, RAÇA E GÊNERO: ELEMENTOS PARA A CONSTRUÇÃo DE UMA TEORIA FEMINISTA DO DIREITO ADEQUADA AO FEMINISMO NEGRO

Mário Lúcio Garcez Calil e Debora Markman

"NeGras VAdiAs": A CRIMINALIZAÇÃo Do CORPO NEGRO QUE OUSA PROTESTAR.

Soraia da Rosa Mendes e Bruno Amaral Machado

A experiênCia do Abaetê Criolo como aÇão de enfrentamento a desigualdades de GÊNERO E RAÇA: UMA ANÁLISE DE DISCURSO SOBRE INTERSECCIONALIDADE

E FEMINISMO NEGRO

David Oliveira e Thalita Terto Costa 
ENTRE A AUSÊNCIA E O EXCESSO: A ATUAÇÃo DO ESTADO SOBRE CORPOS DISSIDENTES 230 Dayane do Carmo Barretos, Klelia Canabrava Aleixo e Vanessa de Sousa Soares

SILÊNCIOS E MITOS NUMA PERSPECTIVA INTERSECCIONAL: DO CONTROLE INFORMAL DE CORPOS AO CONTROLE PENAL DE MULHERES NEGRAS ......................................................248 Elaine Pimentel e Nathália Wanderley

Ministério Público e domínio Racial: poucas ilhas negras EM UM ARQuipélago nãoNEGRO 267

Saulo Murilo de Oliveira Mattos

Políticas públicas Para a ARTiCulaÇão de GÊNERo E RAÇA: MEIOS PARA GARANTir A REPRESENTATIVIDADE POLÍtiCA E JURÍDiCA DA MULHER NEGRA NO BRASIL 296 Mariana Dionísio de Andrade e Eduardo Régis Girão de Castro Pinto

Parte Específica: Incidências Concretas.......................................................... 317

REIMAGING THE POLICING OF GENDER VIOLENCE: LESSONS FROM WOMEN'S POLICE STATIONS IN Brasil AND ArgENTINA............................................................................................ 319 Kerry Carrington, Melissa Bull, Gisella Lopes Gomes Pinto Ferreira e María Victoria Puyol

NECROBIOPOLIÍtica DE GÊNERo No BRASIL CONTEMPORÂNEO: O FEMINICÍDIO EM TEMPOS DE FASCISMO SOCIAL 340 Maiquel Ângelo Dezordi Wermuth e Joice Graciele Nielsson

ViolÊNCIA CONTRA MULHERES QUILOMBOLAS: UMA REFLEXÃo SOBRE A APLICAÇÃo DE UMA PERSPECTIVA INTERSECCIONAL À LUZ DA IDEIA DE CONTRAPÚBLICOS SUBALTERNOS DELINEADA POR FRASER..... 360 Maria Eugenia Bunchaft, Leonardo Rabelo de Matos Silva e Gustavo Proença da Silva Mendonça

Políticas públicas de PREVEnÇÃo aO Feminicídio E INTERSECCIONALIDAdes . 384 Thiago Pierobom de Ávila, Marcela Novais Medeiros, Cátia Betânia Chagas, Elaine Novaes Vieira, Thais Quezado Soares Magalhães e Andrea Simoni de Zappa Passeto

DiREITO DE VIVER SEM VIOLÊNCIA: PROTEÇÃO E DESAFIOS DOS DIREITOS DAS MULHERES indígenas no Sistema InTERAmericano de Direitos Humanos Julia Natália Araújo Santos e Felipe Rodolfo de Carvalho

ANÁlise de GÊNERo E DE CRUZAMENTOS INTERSECCIONAIS DE UM PROGRAMA PARA AUTORES DE VIOLÊNCIA DOMÉSTICA CONTRA AS MULHERES

Mariana Fernandes Távora, Dália Costa, Camilla de Magalhães Gomes e Adriano Beiras

Controle PENAL dA LOUCURA E DO GÊNERO: REFLEXÕES INTERSECCIONAIS SOBRE MULHERES EgRESSAS DA MEdidA DE SEgurANÇA No Rio DE JANEIRO. .468 Bruna Martins Costa e Luciana Boiteux 
ONDE ESTÃo NOSSOS DIREITOS? O CAMPO FEMINISTA DE GÊNERO BORDADO PELAS MULHERES ATINGIDAS POR BARRAGENS

Tchenna Fernandes Maso e Tchella Fernandes Maso

Os SEGREDOS EPISTÊMICOS DO DIREITO DO TRABALHO.

Flávia Souza Máximo Pereira e Pedro Augusto Gravatá Nicoli

Reforma trabalhista e desigualdade de GÊNERo no Brasil: uMa PERSPECTIVA JuRÍdicA E ECONÔMICA

Natalia Branco Lopes Krawczun, Magno Rogério Gomes e Solange de Cassia Inforzato de Souza

A COLONIALIDADE DO PODER NA PERSPECTIVA DA INTERSECCIONALIDADE DE RAÇA E GÊNERO: ANÁLISE DO CASO DAS EMPREGADAS DOMÉSTICAS NO BRASIL .565

Daphne de Emílio Circunde Vieira Andrade e Maria Cecília Máximo Teodoro

COMPETIÇÃO POLÍTICA E DESIGUALDADES DE GÊNERO NAS ELEIÇÕES PARA ASSEMBLEIAS ESTADUAIS EM 2018

Lígia Fabris Campos, Décio Vieira da Rocha, Leandro Molhano Ribeiro e Vitor Peixoto

DisCrit: os LIMITES DA INTERSECCIONALIDADE PARA PENSAR SOBRE A PESSOA NEGRA COM DEFICIÊNCIA

Philippe Oliveira de Almeida e Luana Adriano Araújo

SeÇão III: Temais GeraIS

La Corte Interamericana de Derechos Humanos. Hermenéutica del derecho al MEDIO AMBIENTE SANO, A LA IDENTIDAD CULTURAL Y A LA CONSULTA, A LA LUZ DE LA SENTENCIA “Lhaka Honhat (nUestra tierra) vs. Argentina” (2020)

Juan Jorge Faundes Peñafiel, Cristobal Carmona Caldera e Pedro Pablo Silva Sánchez

LA RESPUESTA INSTITUCIONAL FRENTE A LA TRATA DE PERSONAS EN EL ESTADO DE CHIHUAHUA.

UN ANÁLISIS DE POLÍTICA PÚBLICA .676 Martha Aurelia Dena Ornelas

Comunidades quilombolas, RaCismo e ideologia no discurso de JAIr Bolsonaro: estudo CRÍTICO DOS DISCURSOS POLÍTICO E JUDICIAL 700 Ricardo de Macedo Menna Barreto e Helena Mascarenhas Ferraz

O Princípio Geral da Boa Administração no Código do Procedimento Administrativo Português. Pistas de inVestigação. 724 Ana Melro 


\title{
Controle penal da loucura e do gênero: reflexões interseccionais sobre mulheres egressas da medida de segurança no Rio de Janeiro*
}

\author{
Criminal control of madness and gender: \\ intersectional reflections about women \\ egressed from de security measure in Rio de \\ Janeiro
}

Bruna Martins Costa**

Luciana Boiteux***

\section{Resumo}

Este artigo pretende discutir a relação entre crime e loucura, tendo como foco a condição de mulheres em sofrimento psíquico e mental egressas de medida de segurança de internação no município do Rio de Janeiro. Ele tem como objetivo geral compreender de que forma o controle formal-penal incide sobre as mulheres que cumpriram medida de segurança de internação em estabelecimento de custódia e tratamento psiquiátrico (ECTP) no município do Rio de Janeiro. Parte-se, portanto, de uma pergunta que questiona como o controle formal-penal incide sobre essas sujeitas. Orientada por um referencial interseccional, descolonial e antimanicomial, foi realizada uma investigação teórico-analítica sobre o referido objeto. Com o objetivo de ilustrar essa contribuição, recorreu-se aos aspectos emblemáticos da atuação do controle social formal-penal no caso de transinstitucionalização de uma ex-paciente do Hospital Penal Psiquiátrico Roberto de Medeiros (HPP RM), que foi desinternada durante o primeiro biênio após a implementação pioneira do exame multiprofissional e pericial de avaliação psicossocial (EMPAP) pela Defensoria Pública do Estado do Rio de Janeiro. Como conclusão, foi possível identificar que houve um continum do controle formal-penal para outras formas de controle social, como o controle médico-psiquiátrico, materializado na transinstitucionalização da paciente. Aponta-se para o fato de que o controle social formal-penal parece estar sempre à espreita, esperando que essas mulheres incidam no desvio para serem novamente capturadas pelo sistema de justiça penal. Considera-se, assim, que um extenso caminho precisa ser percorrido no que diz respeito a novos olhares sobre a loucura, bem como há um longo processo de desconstrução e transgressão do ideal hegemônico feminino, ainda hoje a referência de normalidade para as mulheres.

Palavras-chave: Gênero. Loucura. Interseccionalidade. Controle penal. EMPAP. Transinstitucionalização. 


\section{Abstract}

This article intends to discuss the relationship between crime and madness, focusing on the condition of women with mental suffering who have been discharged from a security measure in the city of Rio de Janeiro. It has as its general objective to understand how formal-penal control affects women who have been hospitalized in a custody and psychiatric treatment institution in the city of Rio de Janeiro. It starts, therefore, with a question that inquires how the formal-penal control affects these subjects. Guided by an intersectional, decolonial and anti-asylum referential, a theoretical-analytical investigation was carried out on that object. In order to illustrate this contribution, the emblematic aspects of the performance of formal-penal social control were used in the case of the t transinstitutionalization of an ex-patient at the Roberto de Medeiros Psychiatric Hospital, who was dismissed during the first biennium after the pioneering implementation of the multi-professional and expert psychosocial evaluation by the Public Defender of the State of Rio de Janeiro. As a conclusion, it was possible to identify that there was a continuum of formal-penal control for other forms of social control, such as medical-psychiatric control, materialized in the patient's transinstitutionalization. It points to the fact that social formal-penal control always seems to be lurking, hoping that these women will focus on the diversion to be captured again by the criminal justice system. It is considered, therefore, that a long path needs to be taken with regard to new perspectives on madness, as well as there is still a long process of deconstruction and transgression of the feminine hegemonic ideal, even today the reference of normality for women.

Keywords: Gender. Madness. Intersectionality. Penal control. EMPAP. Transinstitutionalization.

\section{Introdução}

O tema que orienta este trabalho é a discussão sobre crime e loucura, cujo objetivo geral é compreender de que forma o controle formal-penal incide sobre as mulheres que cumpriram medida de segurança de internação em estabelecimento de custódia e tratamento psiquiátrico (ECTP) no município do Rio de Janeiro. Parte-se, portanto, de uma pergunta que questiona como o controle formal-penal incide sobre essas sujeitas.

Desde a publicação da Lei da Reforma Psiquiátrica brasileira (Lei n. 10.216/2001), já se passaram quase 20 anos e, apesar da concretização de projetos louváveis, pouco se caminhou em direção de uma real abolição das instituições de caráter manicomial. No âmbito jurídico, apesar das medidas de segurança de internação seguirem sendo aplicadas, algumas iniciativas, como o exame multiprofissional e pericial de avaliação psicossocial (EMPAP), vêm problematizando esse recurso e se consolidando por meio do uso contra hegemônico do direito.

Nos últimos anos, houve aumento significativo de investigações acerca do encarceramento feminino, razão pela qual a discussão sobre as mulheres em sofrimento psíquico e mental em conflito com a lei ganhou impulso e começou a sair da invisibilidade. Contudo, ainda que algumas pesquisas tratem especificamente de mulheres em cumprimento de medida de segurança de internação e/ou institucionalizadas em estabelecimentos de custódia e tratamento psiquiátrico (ECTPs), poucos são os trabalhos que, como este, investigam a condição das egressas.

Este texto é parte de uma pesquisa empírica já finalizada, que utilizou como metodologia o estudo de caso com suporte na pesquisa documental, e que elegeu como objeto de estudo a transinstitucionalização de uma paciente, no município do Rio de Janeiro, após a implementação pioneira do exame multiprofissional e pericial de avaliação psicossocial (EMPAP) pela Defensoria Pública do Estado do Rio de Janeiro (DPERJ).

Neste artigo, limitar-nos-emos a apresentar o aporte teórico que subsidiou o desenvolvimento da pesquisa apresentada neste artigo e, de forma ilustrativa, os aspectos emblemáticos da atuação do controle social 
formal-penal sobre as mulheres em sofrimento psíquico que estiveram institucionalizadas em virtude da medida de segurança. Apesar da opção por privilegiar o aspecto teórico-analítico, é importante mencionar que as reflexões trazidas estão fundamentadas no diálogo constante entre teoria e prática.

Debruçar-nos-emos sobre a condição das egressas do Hospital Penal Psiquiátrico Roberto de Medeiros (HPP RM) que foram contempladas pelo EMPAP entre os anos de 2017 e 2018, o primeiro biênio após a implementação do projeto. Interessa-nos saber como controle social formal-penal se manteve presente em suas vidas e como outras formas de controle passaram a agir. Para tornar mais palpáveis essas reflexões, traremos o caso de uma paciente que não foi realmente desinstitucionalizada, mas transinstitucionalizada. A transinstitucionalização é marcada, como o próprio termo sugere, pela manutenção do controle institucional ainda que haja o deslocamento de um estabelecimento, de uma instituição total, para outra.

No transcorrer deste artigo, buscaremos mostrar que, em relação às mulheres, os mecanismos de controle social informal e formal existem simultânea e concomitantemente. Ao tratarmos das mulheres em sofrimento psíquico e mental em conflito com a lei, traremos que, uma vez que é inerente à medida de segurança a coexistência dos controles formal-penal e médico-psiquiátrico, a transinstitucionalização apenas enseja o deslocamento de algumas atribuições do primeiro para o segundo mecanismo, na forma de um continum. É possível dizer que, mesmo as mulheres que foram desisntitucionalizadas, continuam a sentir os efeitos do controle formal-penal que, apesar de perder sua predominância em relação a outros mecanismos de controle social informal e formal, mantém-se sempre à espreita.

Entendemos que as experiências não são compartilhadas da mesma forma e, quando tratamos de mulheres privadas de liberdade, é fundamental explicitar sua raça e sua classe, uma vez que são fatores relacionados à seletividade do sistema de justiça penal. Assim, os conceitos e as reflexões desenvolvidos estão amparados por uma lente interseccional, descolonial e antimanicomial. Sobre a importância de se adotar essa postura na pesquisa, Vanessa Berner afirma que

O feminismo negro, o pós-colonial, o lésbico e outros, se colocam contra essa ideia de uma categoria homogênea e universal de "mulher" como sujeito político e de direito, justamente por se tratar de uma categoria que, por representar valores ocidentais, exclui outras categorias de mulheres. Sua reivindicação é a interseccionalidade, cujo propósito é encontrar fórmulas que considerem a soma das diferentes desigualdades, como raça, sexo, classe social, orientação sexual etc. Fórmulas que sejam capazes de conceber sujeitos como categorias sociais heterogêneas. O feminismo interseccional pretende diminuir as assimetrias e as opressões por meio da visibilidade e da heterogeneidade ${ }^{1}$.

\section{Processos de subjetivação femininos e controle social}

Entende-se por processo de subjetivação os discursos, mecanismos, ferramentas mobilizadas e envolvidas na (trans)formação do indivíduo enquanto sujeito, no tornar-se pessoa constituída por uma, ou múltiplas, identidades ${ }^{2}$. De modo mais específico, propusemo-nos a compreender como o controle social formal-penal opera sobre as mulheres que cumpriram uma medida de segurança de internação, desviando, dessa forma, do ideal hegemônico feminino moderno da sociedade brasileira.

A opção pela adoção de uma lente interseccional, descolonial e antimanicomial justifica-se pela imprescindibilidade de racializarmos os debates sobre as sujeitas privadas de liberdade, bem como localizá-los nas classes sociais das quais a maioria delas provém, tendo em vista que as experiências das mulheres são bas-

\footnotetext{
BERNER, Vanessa de Oliveira Batista. Teorias feministas: o direito como ferramenta de transformação social. In: BERTOLIN, Patrícia Tuma Martins; ANDRADE, Denise Almeida de; MACHADO, Monica Sapucaia (org.). Mulher, sociedade e vulnerabilidade. Erechim: Deviant, 2017. p. 29-46. p. 41.

2 HENNINGEN, Inês; GUARESCHI, Neuza Maria de Fátima. A subjetivação na perspectiva dos estudos culturais e foucaultianos. Psicologia da Educação, São Paulo, n. 23, p. 57-64, 2006.
} 
tante distintas e que inexiste a mulher como categoria universal.

O termo interseccionalidade engloba a inseparabilidade entre racismo, capitalismos e cisheteropatriarcado, e ficou popularmente conhecido nos anos 2000, a partir do uso feito por Kimberlé Crenshaw ${ }^{3}$. Akotirene dispõe sobre uma interseccionalidade que forneça instrumentos para enxergar a matriz colonial moderna contra os grupos oprimidos, adequando-se às demandas da brasilidade. Para tanto, defende uma perspectiva descolonial transdisciplinar, que trate da instrumentalidade do gênero, da raça, da classe e da nação; da sensibilidade interpretativa em relação aos efeitos identitários; da atenção global para a matriz colonial moderna, evitando o desvio analítico para apenas um eixo de opressão ${ }^{4}$.

No mesmo sentido, Lugones propõe um feminismo descolonial, que revele questões ocultas de gênero, raça e sexualidade, e que promova uma releitura da própria modernidade capitalista colonial moderna. Para a autora, a imposição colonial do gênero permeia diversas esferas da sociedade, do conhecimento, do cotidiano, destacando-se os impactos da colonização como forma de dominação, inclusive, em relação às mulheres ${ }^{5}$.

Importante pontuar que esse termo se difere de colonialismo, uma vez que busca chamar a atenção para as continuidades históricas entre os tempos coloniais e "pós-coloniais". Preocupa-se, também, em mostrar que as relações coloniais de poder não se limitam ao domínio político-econômico e jurídico-administrativo dos centros sobre as periferias, mas possuem também uma dimensão epistêmico-cultural ${ }^{6}$.

Interseccionalidade e descolonialidade são importantes instrumentos teórico-metodológicos, uma vez que contemplam as mulheres negras, indígenas, lésbicas, terceiro-mundistas, que estão longe das cisgeneridade branca heteropatriarcal que fundamenta o modelo feminino hegemônico. Precisam, portanto, ser utilizados para a elaboração de metodologias adequadas à realidade desses grupos, de modo que possam mobilizá-los para responder à sua condição de opressão.

As tecnologias de gênero são importantes constituidoras dos dispositivos, pois interpelam ideais culturais e performances de gênero. Também estão presentes em diversas esferas, que vão desde as produções simbólicas midiáticas às regras de comportamentos cotidianos. Nesse sentido, os sujeitos se constituem por meio de processos de subjetivação que se dão por meio de interações sociais, bem como pela relação do sujeito consigo mesmo?

Os dispositivos dos processos de subjetivação não são os mesmos para homens e mulheres: os primeiros seriam privilegiadamente subjetivados pelo dispositivo da eficácia ${ }^{8}$, baseado na virilidade sexual e laborativa, e as segundas, pelos dispositivos materno e amoroso. Os processos de subjetivação gendrados ${ }^{9}$ criam, também, vulnerabilidades identitárias específicas e diferenciadas, evidenciadas no sofrimento psíquico.

Esses dispositivos não existem ontologicamente, sendo, portanto, categorias analíticas situadas e historicizadas. Desse modo, a utilização de um referencial interseccional e descolonial permite que relacionemos as vulnerabilidades de raça/etnia, classe, sexualidade e território aos distintos processos de subjetivação femininos.

\footnotetext{
COLLINS, Patricia Hill. Black, feminist thought. New York: Routledge, 2009.

AKOTIRENE, Carla. Interseccionalidade. São Paulo: Pólen, 2019.

5 LUGONES, María. Colonialidad y género. Tabula Rasa, Bogotá, n. 9, p. 73-101, jul./dez., 2008.

${ }^{6}$ CASTRO-GÓMEZ, Santiago; GROSFOGUEL, Ramón. Prólogo: Giro decolonial, teoria crítica y pensamento heterárquico. In: CASTRO-GÓMEZ, Santiago; GROSFOGUEL, Ramón. (Comp.). El Giro Descolonial: reflexiones para uma diversidade epistémica más allá del capitalismo global. Bogotá: Siglo del Hombre Editores, 2007. p. 9-24.

ZANELLO, Valeska. Saúde mental, gênero e dispositivos: cultura e processos de subjetivação. Curitiba: Appris, 2018. p. 56-57.

8 Para uma compreensão aprofundada sobre o dispositivo da eficácia, ver: ZANELLO, Valeska. Saúde mental, gênero e dispositivos: cultura e processos de subjetivação. Curitiba: Appris, 2018.

9 Temos priorizado a utilização dessa grafia ao invés de engendrado com o intuito de evitar uma confusão entre ideias distintas.
} 


\section{Quando os scripts não são suficientes: do controle social informal ao controle social formal-penal}

Para uma melhor compreensão acerca da forma como o controle social formal-penal age em relação às mulheres que desviam de um ideal feminino hegemônico, faz-se necessária uma breve incursão histórica.

No início do século XX, a maior frequência das mulheres nos espaços coletivos ${ }^{10}$ e as alterações nas relações dentro do próprio ambiente doméstico levaram tabus relacionados ao trabalho e a sexualidade a extravasar a dimensão privada. Essas mudanças ensejaram críticas de grupos que temiam a quebra dos valores morais vigentes, e uma resposta a esse avanço foi a constante vigilância masculina. As instituições prisionais femininas surgiram no Brasil no final da primeira metade desse século, e buscaram conciliar elementos econômicos, morais e religiosos, por meio do trabalho, da disciplina, do silêncio, do isolamento e da oração.

As formas de controle social que incidiam, e incidem, sobre as mulheres eram tanto de natureza informal, exercidas pela família, opinião pública, trabalho, escola, igreja, medicina, quanto formal ${ }^{11}$, colocadas em prática pelos órgãos estatais. Apesar de apresentarem suas próprias dinâmicas de funcionamento, é comum que esses mecanismos de controle ajam simultaneamente e em conjunto.

As exigências impostas às mulheres mães, dona de casas, esposas, trabalhadoras — principalmente no caso das mulheres negras - eram contraditórias entre si, sendo impossível conciliá-las satisfatoriamente. Nesse sentido, a incapacidade de dar conta de todos esses papéis era vista, por um lado, como incompetência e inabilidade, e, por outro, como desvio do ideal feminino hegemônico branco. A falta de características essencialmente femininas era associada aos comportamentos subversivos e vice-versa, atribuindo-se às mulheres desviantes estereótipos em virtude da condição de anormalidade.

Os não lugares de mulher eram ocupados pelas prostitutas, lésbicas, "loucas", solteironas ${ }^{12}$, negras, indígenas e por aquelas que não tinham profissão definida. O elemento constitutivo desse locus passava pela sexualidade considerada desregrada, "anormal", dessas mulheres, ainda que outras características naturalmente femininas também estivessem ausentes. Aos excessos e descaminhos do padrão sexual normal ${ }^{13}$ eram atribuídas as descontinuidades do feminino e, consequentemente, as rupturas em relação a determinadas performances e papéis ${ }^{14}$.

A busca pela anormalidade era mais refinada e incisiva no caso das mulheres. Diante da grande variedade de desvios possíveis, a loucura feminina recebeu especial atenção da literatura médica, que associava a incidência de transtornos mentais à condição de sexualidade reduzida ou demasiadamente exacerbada, e se constituiu de forma bastante própria. O descumprimento de qualquer papel considerado tipicamente feminino era suficiente para que se consumasse o desvio e, quase como consequência inerente, se caracterizasse o distúrbio de ordem psíquica.

\footnotetext{
10 As mulheres negras já haviam deixado seus lares há muito tempo, e ocupavam os espaços públicos, sendo ainda mais censuradas do que as mulheres brancas. DAVIS, Angela. Mulheres, raça e classe. São Paulo: Boitempo, 2016.

11 A própria legislação brasileira criou uma série de dispositivos que garantiam total supremacia e controle dos homens sobre as mulheres, e que endossavam um ideal de família burguesa legalmente constituída por meio do casamento. O Código Civil de 1916 reforçava uma divisão sexual do trabalho, enfatizando a posição de chefe de família e provedor, do homem, e de mãe, dona de casa e esposa submissa, da mulher. As mulheres necessitavam de autorização expressa dos maridos caso quisesse trabalhar fora. Além da legislação civil, as Constituições de 1934 e 1937 eram bastante enfáticas ao mencionar em seus textos a importância da família. O Código Penal de 1940, em seu artigo 215 também considerava que só podia ser vítima de condutas contra a "dignidade sexual” a "mulher honesta", expressão esta que só foi suprimida pela Lei n. 12.015/2009.

12 ZANELLO, Valeska. Saúde mental, gênero e dispositivos: cultura e processos de subjetivação. Curitiba: Appris, 2018.

13 A heterossexualidade monogâmica passou a ser, a partir de meados do século XIX, a conduta sexual paradigmática da normalidade, devendo a mulher se adequar a esse parâmetro, sob o risco de incorrer no desvio. Por outro lado, do homem sempre foi esperada a transgressão da monogamia. ZANELLO, Valeska. Saúde mental, gênero e dispositivos: cultura e processos de subjetivação. Curitiba: Appris, 2018.

14 ANGOTTI, Bruna. Entre as Leis da Ciência, do Estado e de Deus: o surgimento dos presídios femininos no Brasil. 2. ed. San Miguel de Tucumán: Universidad Nacional de Tucumán; Instituto de Investigaciones Históricas Leoni Pinto, 2018.
} 
Houve, também, a condenação das formas de vida de pessoas pobres e negras, que habitavam lugares degradados da cidade em crescimento - espaços estes associados ao outro, à classe perigosa, e que, em virtude disso, deviam ser erradicados ${ }^{15}$. A essa população era voltado um controle social bem mais duro, que operava tanto de modo informal, sobre a mobilidade dos corpos negros, como de modo formal, a partir de forças institucionalizadas de repressão policial ${ }^{16}$.

Essa estigmatização do modo de vida popular deve ser analisada a partir de uma perspectiva racializada. Eram nos espaços degradados, marginais, que viviam ex-escravizados, negros e negras, mestiços. A associação entre a negritude, o atraso e a degenerescência era frequente, existindo uma preocupação por parte de médicos, sanitaristas e teóricos brasileiros ligados ao movimento eugenista, que presumiam que doenças sociais estavam relacionadas à questão racial ${ }^{17}$.

As mulheres negras são historicamente as mais marginalizadas: em momento algum, satisfizeram o ideal hegemônico e estavam fadadas a integrar a categoria de desviante quando o controle social informal não era capaz de estabelecer limites. Assim, era possível criminalizá-las pelo desvio do ideal hegemônico feminino, por sua raça e classe.

Uma vez que o conteúdo das leis e o conceito de crime não são universais, o mesmo pode ser dito da categoria mulher criminosa, uma vez que ela só passa a existir a partir do momento em que há delineação de quem pode ser considerada delinquente e de quais são as atitudes e o locus próprios da delinquência. Depois da atribuição do rótulo, ela ainda precisa ser julgada e condenada para fazer jus ao estigma.

Há, portanto, escolhas prévias do sistema penal que indicam condutas e apontam quem são os sujeitos privilegiados no processo de criminalização e de vitimização ${ }^{18}$. Essa seleção é pautada na associação entre delinquência, classe social, raça, localização espacial dos sujeitos no território, gênero e sexualidade.

$\mathrm{Na}$ natureza feminina residiam tanto os problemas como a salvação ${ }^{19}$, pois quanto maior fosse a proximidade com fatores "civilizatórios" 20 , menor seria o potencial desviante de uma mulher. Por um lado, deveriam ser incentivados os aspectos positivos, como o potencial de reprodução e de cuidado. Por outro, os aspectos negativos, como a sexualidade não reprodutiva e a loucura, deveriam ser afastados com o auxílio da moral, da educação e da medicina. Se esse ideal hegemônico de mulher era difícil de ser satisfeito por brancas e burguesas, mulheres negras, pobres, descendentes de escravizados foram excluídas desse padrão ${ }^{21} \operatorname{logo}$ em sua gênese.

Analisando a construção de estereótipos femininos normais e desviantes, é possível identificar permanências significativas, tanto no senso comum quanto em práticas e abordagens consideradas inovadoras e respaldadas cientificamente. Ainda temos muito a percorrer no sentido de romper com padrões e ideais moralizantes que incidem sobre as mulheres, sejam eles na forma de ferramentas de controle ou mascarados de instrumentos de conquista por direitos e liberdades.

\footnotetext{
15 ANGOTTI, Bruna. Entre as Leis da Ciência, do Estado e de Deus: o surgimento dos presídios femininos no Brasil. 2. ed. San Miguel de Tucumán: Universidad Nacional de Tucumán; Instituto de Investigaciones Históricas Leoni Pinto, 2018; ZANELLO, Valeska. Saúde mental, gênero e dispositivos: cultura e processos de subjetivação. Curitiba: Appris, 2018.

16 BORGES, Juliana. O que é encarceramento em massa? Belo Horizonte: Letramento, 2018.

17 GÓES, Luciano. A "tradução" de Lombroso na obra de Nina Rodrigues: o racismo como base estruturante da criminologia brasileira. Rio de Janeiro: Revan, 2016.

18 ANDRADE, Vera Regina Pereira de. A ilusão da segurança jurídica: do controle da violência a violência do controle penal. Porto Alegre: Livraria do Advogado, 1997.

19 COUTO, Rita Cristina Carvalho de Medeiros. Eugenia, loucura e condição feminina. Cadernos de Pesquisa, São Paulo, n. 90 , p. 52-61, 1994.

20 ANGOTTI, Bruna. Entre as Leis da Ciência, do Estado e de Deus: o surgimento dos presídios femininos no Brasil. 2. ed. San Miguel de Tucumán: Universidad Nacional de Tucumán; Instituto de Investigaciones Históricas Leoni Pinto, 2018.

21 A própria estrutura capitalista moderna colonial que cunha esse estereótipo de mulher ideal o torna inalcançável para as fêmeas colonizadas, negras, já pressupondo que o caminho que mais facilmente percorrerão é o do desvio. Não é acidental que as mulheres negras tenham sempre trabalhado fora de seus lares, nem que sejam as mais perseguidas pelo controle penal. LUGONES, María. Colonialidad y género. Tabula Rasa, Bogotá, n. 9, p. 73-101, jul./dez., 2008.
} 


\section{Crítica ao controle penal da loucura e alternativas antimanicomiais no sistema de justiça}

Nessa etapa do trabalho, introduziremos o instituto da medida de segurança, que justifica a privação de liberdade para as mulheres tidas como loucas e criminosas simultaneamente, e o EMPAP, importante projeto antimanicomial que subverteu os critérios de desinternação das mulheres aprisionadas por se enquadrarem nesses parâmetros.

Entende-se por antimanicomial o movimento, os projetos, as diretrizes, as medidas etc., que se opõem à lógica de contenção da loucura própria dos manicômios. Esta tem como sustentáculo as instituições totais, com características asilares, que focam na loucura como doença e não na pessoa que busca o tratamento.

O termo ganhou popularidade no Brasil a partir das críticas dos movimentos sociais pela Reforma Psiquiátrica brasileira. Apesar de ter resultado na promulgação da Lei n. 10.216/2001, esse processo continua em curso e se desdobra de forma bastante heterogênea. Ele é marcado pela disputa entre um projeto radical, em favor de uma sociedade sem manicômios e pautado nos princípios do Manifesto, de 1987, e da Carta de Bauru, de 2017, e um projeto em favor da manutenção do status quo, alinhado aos interesses neoliberais e capitalistas ${ }^{22}$.

Ainda que a experiência da psiquiatria democrática e da antipsiquiatria tenham servido como importantes inspirações, elas não foram modelos seguidos à risca. Apesar de o Brasil ter desenvolvido sua própria metodologia para a implementação da reforma psiquiátrica, Passos chama atenção para o fato de que a questão racial sofreu um apagamento ao longo de todo esse processo, sendo urgente sua retomada, em observância aos princípios sintetizados no Manifesto e na Carta de Bauru².

São múltiplos os saberes e fazeres que têm identificado fissuras e possibilidades de resistência em relação aos saberes hegemônicos, enfatizando a necessidade do redirecionamento da assistência psiquiátrica no país. No campo do direito, penalistas e criminólogos críticos há tempos criticam o caráter lacunoso da utilização das medidas de segurança, tendo em vista que sua regulamentação pelo Código Penal, Código de Processo Penal e Lei de Execução Penal é bastante imprecisa, dando margem para grandes violações das garantias fundamentais já asseguradas aos sujeitos imputáveis condenados ao cumprimento de penas comuns.

Segundo o artigo 26 do Código Penal, é considerada inimputável a pessoa que apresenta algum transtorno psíquico ou mental que a torna incapaz de compreender a dimensão reprovável de seu ato e, portanto, não torna passível sua responsabilizaçãa ${ }^{24}$. A esse sujeito, no caso do cometimento de uma conduta prevista na legislação penal, se comprovada sua inimputabilidade, é atribuída uma sentença absolutória imprópria, que tem como consequência a exigência do cumprimento de uma medida de segurança, em meio aberto ou fechado.

A medida de segurança, com base no ponto de vista da dogmática, não é propriamente uma pena, uma vez que o inimputável não é considerado agente de um crime propriamente dito. Sua condição psíquica e mental torna viciado o elemento da culpabilidade de sua ação, ainda que ela seja considerada típica e antijurídica.

No Brasil, a forma de conciliar os interesses do cientificismo positivista e da metafísica do direito penal

\footnotetext{
22 PASSOS, Rachel Gouveia. Frantz Fanon, reforma psiquiátrica e luta antimanicomial no Brasil: o que escapou nesse processo? Sociedade em Debate, Pelotas, v. 25, n. 3, p. 74-88, set./dez., 2019.

23 PASSOS, Rachel Gouveia. "Holocausto ou navio negreiro?”: inquietações para a Reforma Psiquiátrica Brasileira. Argum, Vitória, v. 10, n. 3, p. 10-22, set./dez., 2018.

24 No que diz respeito à responsabilização dos sujeitos em sofrimento psíquico, há importantes divergências teóricas e políticas sobre a total impossibilidade destes sujeitos serem responsabilizados. Tem-se articulado em favor da compreensão de que esses sujeitos podem ser responsabilizados na medida em que sua condição possibilita, contribuindo, inclusive, para o processo de constituição de sua cidadania e autonomia.
} 
clássico se manifestou sob a forma de ideologia de defesa social ${ }^{25}$. A partir de sua lógica, estruturou-se no sistema do duplo binário, no Código Penal de 1940, que instituiu dois tipos de reações penais para os imputáveis.

A pena seria a reação penal calculada com base na culpabilidade e na gravidade do ato, enquanto a medida de segurança seria indicada com base na periculosidade, ou seja, no estado de antissociabilidade, no juízo de probabilidade de delinquência futura baseado na "anomalia" psíquica do agente ${ }^{26}$, levando ao seu aprisionamento e atribuindo-lhe um tratamento curativo. A primeira reação satisfaria a ânsia daqueles que consideravam necessária a expiação da culpa, enquanto a segunda contemplaria aqueles que viam como indispensável o tratamento e o isolamento do indivíduo criminoso.

Após alguns anos, esse modelo foi reformulado, levando a medida de segurança a ser aplicada somente aos inimputáveis e, em alguns casos, aos semi-imputáveis ${ }^{27}$. Em virtude de ter se fundado em mais de uma tradição teórico-filosófica ${ }^{28}$, nosso direito penal aplica, simultaneamente, as lógicas da culpabilidade e da periculosidade, e, consequentemente, a pena e a medida de segurança ${ }^{29}$.

Uma das grandes problemáticas em torno deste instituto é sua escassa regulamentação jurídica. Além disso, se, em teoria ela, é considerada um tratamento, na prática, verifica-se que ela muito pouco se distingue de uma pena - os estabelecimentos de custódia e tratamento psiquiátrico $\left(\right.$ ECTPs $^{30}$ ) geralmente ficam em complexos penitenciários, os pacientes ficam em celas gradeadas, os profissionais responsáveis pela instituição são agentes penitenciários, os hospitais de custódia e tratamento psiquiátrico (HCTPs) estão sujeitos às regulamentações da administração penitenciária, etc.

Sobre o saber psiquiátrico e sua inserção no campo forense, Foucault menciona que essa parceria começa a se estabelecer durante o século XIX, quando alguns tipos específicos de criminosos começam a cumprir pena em hospitais psiquiátricos ${ }^{31}$. A psiquiatria forense encontra nesse período sua área de domínio, entre os saberes jurídico e psiquiátrico. Há, portanto, o preenchimento de uma lacuna com a elaboração de um discurso especificamente direcionado à loucura criminal. Esse discurso, esse saber, é voltado para a normalização dos indivíduos e não para a prevenção do crime ou para a cura da doença mental ${ }^{32}$.

O principal reflexo contemporâneo desse movimento da psiquiatria forense parece ter se concentrado nos exames psiquiátricos. Como requisito para a extinção da medida de segurança, é necessária a realização do exame de verificação de cessação de periculosidade (EVCP). O responsável pelo exame é o médico psiquiatra, que fica responsável por atestar se o paciente é ou não perigoso, se está ou não apto para deixar o estabelecimento de custódia e recomeçar sua vida em sociedade.

A perícia psiquiátrica se dedica a demonstrar que o indivíduo já era potencialmente desviante antes mesmo de cometer qualquer ilícito. Suas características são tomadas como causas e seus defeitos passam a ser

25 BARATTA, Alessandro. Criminologia crítica e crítica do direito penal: introdução à sociologia do direito penal. 3. ed. Rio de Janeiro: Revan, 2002.

26 CARVALHO, Salo de; WEIGERT, Mariana de Assis Brasil e. Sofrimento e clausura no Brasil contemporâneo: estudos críticos sobre fundamentos e alternativas às penas e medidas de segurança. Florianópolis: Empório do Direito, 2017. p. 76.

27 CARVALHO, Salo de; WEIGERT, Mariana de Assis Brasil e. Sofrimento e clausura no Brasil contemporâneo: estudos críticos sobre fundamentos e alternativas às penas e medidas de segurança. Florianópolis: Empório do Direito, 2017.

28 COSTA, Bruna Martins. Aprisionamento da loucura: internamento, psiquiatrização e controle penal. 2017. Monografia (Bacharelado em Direito) - Universidade Federal de Santa Catarina, Florianópolis, 2017.

29 CARVALHO, Salo de; WEIGERT, Mariana de Assis Brasil e. Sofrimento e clausura no Brasil contemporâneo: estudos críticos sobre fundamentos e alternativas às penas e medidas de segurança. Florianópolis: Empório do Direito, 2017.

30 Estabelecimento de custódia e tratamento psiquiátrico (ECTPs) é o gênero de instituições que abrigam pessoas em cumprimento de medida de segurança de internação. Dentro dos ECTPs estão contidos os hospitais de custódia e tratamento psiquiátrico (HCTPs), mas também as alas de tratamento psiquiátrico em unidades onde não há espaços especialmente construídos para esta clientela. DINIZ, Débora. A custódia e o tratamento psiquiátrico no Brasil: Censo 2011. Brasília: Letras Livres, 2013.

31 FOUCAULT, Michel. Os anormais: curso no Collège de France (1975-1976). 3. ed. São Paulo: Martins Fontes, 2001.

32 COSTA, Bruna Martins. Aprisionamento da loucura: internamento, psiquiatrização e controle penal. 2017. Monografia (Bacharelado em Direito) - Universidade Federal de Santa Catarina, Florianópolis, 2017. p. 43. 
penalizáveis. O saber forense não tem verdadeiro valor de conhecimento. Contudo, apesar de se limitar a reproduzir enunciados em torno de conteúdos moralizantes, seu poder está no teor do discurso que consiste em transformar o sujeito em objeto de uma tecnologia de segregação e de correção ${ }^{33}$.

Este parece, portanto, ser o verdadeiro fundamento da periculosidade, sob o qual se alicerça a medida de segurança no Código Penal brasileiro. Ela não pode ser uma categoria autenticamente jurídica, porque não opera no mesmo nível de abstração das suas construções formais, bem como não pode ser exclusivamente médica, uma vez que sua finalidade está muito mais próxima de estratégias de controle do que de estratégias terapêuticas.

Essa tentativa de conciliar enunciados moralizantes típicos do controle social, com enunciados do controle jurídico-penal, resulta em inconsistências teóricas e metodológicas que, em última instância, levam a contradições legais. Essa consequência pode ser facilmente observada na dificuldade de aceitação das diretrizes da Lei da Reforma Psiquiátrica brasileira pelo direito penal. Especialmente no caso das mulheres em sofrimento psíquico vinculadas ao sistema penal, sua condição de invisibilidade ${ }^{34}$ não foi alterada com as conquistas da reforma psiquiátrica.

Tendo em vista que essas incongruências são inerentes à lógica da medida de segurança, é fundamental adotar ativamente uma postura crítica, no sentido de produzir novos paradigmas de cuidado das pessoas em sofrimento psíquico e de compreensão da loucura. O EMPAP surge no interior do movimento de superação desse instituto, o principal símbolo da herança periculosista e manicomial do positivismo criminológico e da psiquiatria tradicional, que persiste ainda nos dias de hoje.

\section{0 funcionamento do EMPAP: projeto terapêutico singular, desinternação e desinstitucionalização}

Apesar do crescimento veloz da população carcerária brasileira nos últimos anos, no estado do Rio de Janeiro, verificou-se a queda do número de institucionalizações, especialmente no que diz respeito às pessoas internadas em ECTPs: em 2011 eram 341 pacientes e em 2018 esse número caiu para 184. Magno e Boiteux produzem uma interessante sistematização de informações, publicada na forma de tabelas, para respaldar tal constatação ${ }^{35}$.

As pessoas com transtorno mental em conflito com a lei penal, de acordo com as recomendações do Conselho Nacional de Política Criminal e Penitenciária (CNPCP) ${ }^{36}$, que estabelecem o ano de 2020 como

33 FOUCAULT, Michel. Os anormais: curso no Collège de France (1975-1976). 3. ed. São Paulo: Martins Fontes, 2001.

34 A Portaria Interministerial MJ/SPM n. 210/2014, que instituiu a Política Nacional de Atenção às Mulheres em Situação de Privação de Liberdade e Egressas do Sistema Prisional, quase nada modificou a situação de invisibilidade das mulheres em sofrimento psíquico que entraram em conflito com a lei penal. Essa negligência se reflete nos dados (não) contidos nos INFOPEN Mulheres. BRASIL. Ministério da Justiça. Portaria Interministerial n. 210, de 16 de janeiro de 2014. Institui a Política Nacional de Atenção às Mulheres em Situação de Privação de Liberdade e Egressas do Sistema Prisional, e dá outras providências. Disponível em: http://www.lex.com.br/legis_25232895_PORTARIA_INTERMINISTERIAL_N_210_DE_16_DE_JANEIRO_DE_2014. aspx. Acesso em: 9 fev. 2020; BRASIL. Ministério da Justiça. Levantamento Nacional de Informações Penitenciárias - INFOPEN Mulheres, 2014. Disponível em: https://www.justica.gov.br/news/estudo-traca-perfil-da-populacao-penitenciaria-feminina-no-brasil/ relatorio-infopen-mulheres.pdf. Acesso em: 9 fev. 2020; BRASIL. Ministério da Justiça e Segurança Pública. Levantamento Nacional de Informacõos Penitenciárias - INFOPEN Mulheres, 2018. Disponível em: http://depen.gov.br/DEPEN/depen/sisdepen/infopen-mulheres/infopenmulheres_arte_07-03-18.pdf. Acesso em: 9 fev. 2020; BRASIL. Ministério da Justiça e Segurança Pública. Levantamento Nacional de Informações Penitenciárias - INFOPEN Mulheres, 2019. Disponível em: http://depen.gov.br/DEPEN/depen/sisdepen/ infopen-mulheres/copy_of_Infopenmulheresjunho2017.pdf. Acesso em: 19 mar. 2020.

35 MAGNO, Patrícia Carlos.; BOITEUX, Luciana. Quando a luta antimanicomial mira no manicômio judiciário e produz desencarceramento: uma análise dos arranjos institucionais provocados pela defensoria pública no campo da política pública penitenciária e de saúde mental. Revista Brasileira de Políticas Públicas, Brasília, v. 8, n. 1, p. 574-604, 2018. p. 584-587.

36 BRASIL. Ministério da Justiça e Segurança Pública. Conselho Nacional de Política Criminal e Penitenciária. Exposição de motivos, 2019. Disponível em: http://depen.gov.br/DEPEN/cnpcp-divulga-de-consulta-publica-do-plano-nacional-de-politica-criminal-e- 
sendo o prazo final para que instituições manicomiais deixem de existir no país, e da Lei da Reforma Psiquiátrica, devem, desde o primeiro momento, ser encaminhadas para a Rede de Atenção Psicossocial (RAPS).

Entretanto, no que diz respeito ao imediato atendimento em saúde mental, isso nem sempre se concretiza. Ele está diretamente relacionado "ao carro que chega primeiro": se for a viatura da polícia, a resposta dar-se-á pela via do direito, se for a ambulância, a resposta dar-se-á pela via da saúde. Além disso, dificilmente veremos o prazo estabelecido pelo CNPCP ser cumprido, tendo em vista que estamos perto da data limite e longe de interrompermos as atividades das instituições com características asilares e manicomiais. Isso revela que o principal desafio para o encerramento dos manicômios judiciários no Rio de Janeiro está no "fechamento da porta de entrada".

De 2015 a 2018 essa redução se acentuou ${ }^{37}$, e a implementação do EMPAP veio no sentido de incrementar essa queda. Foi durante esse intervalo que se desdobrou a articulação interinstitucional produtora do projeto e que se encerrou as atividades do HCTP Heitor Carrilho, o mais antigo manicômio judiciário brasileiro $^{38}$. Magno e Boiteux chamam atenção para esse fenômeno, que vai na contramão de uma tendência de aumento da população privada de liberdade do Brasil, hoje com a terceira maior população penitenciária do mundo ${ }^{39}$. Em outras palavras, o aumento da desinstitucionalização ${ }^{40}$ no Rio de Janeiro foi de encontro ao aumento do número de presos imputáveis no Brasil como um todo.

A Defensoria Pública do Estado do Rio de Janeiro, ainda que em um contexto pouco otimista, iniciou a construção de uma política pública que parte da perspectiva antimanicomial e do diálogo entre saberes. O EMPAP veio para substituir o exame de verificação de cessação de periculosidade (EVCP), ainda utilizado em outros estados para atestar a cessação de periculosidade dos pacientes que já cumpriram o tempo mínimo de internação imposto pela LEP e que ambicionam ser desinternados. É um projeto que busca trazer para o sistema prisional as diretrizes da Lei n. 10.216/2001, uma vez que o direito penal é bastante reticente em incorporá-las.

Magno entende que, em observação à lei antimanicomial, todos os institutos de direito penal e processual penal deveriam ser submetidos a uma releitura, especialmente no que tange à execução das medidas de segurança ${ }^{41}$. A lógica antimanicomial incorporada pela Lei da Reforma Psiquiátrica brasileira provocou uma

penitenciaria/PNPCP220919.pdf. Acesso em: 9 fev. 2020.

37 MAGNO, Patrícia Carlos.; BOITEUX, Luciana. Quando a luta antimanicomial mira no manicômio judiciário e produz desencarceramento: uma análise dos arranjos institucionais provocados pela defensoria pública no campo da política pública penitenciária e de saúde mental. Revista Brasileira de Politicas Públicas, Brasília, v. 8, n. 1, p. 574-604, 2018.

38 Em abril de 1921, foi inaugurado o primeiro manicômio, tendo sua origem na Seção Lombroso do Hospício Nacional dos Alienados, na Praia Vermelha. No Brasil, esta instituição antecedeu a própria regulamentação da medida de segurança, ou seja, a necessidade social de manter os loucos criminosos em instituições típicas do controle penal já se manifestava antes da consolidação de um entendimento doutrinário. FUNDAÇÃO OSWALDO CRUZ. Guia de fontes e catálogos de acervos e instituições para pesquisa em saúde mental e assistência psiquiátrica no estado do Rio de Janeiro. Rio de Janeiro: LAPS, 2004. Disponível em: http://bvsms.saude.gov. br/bvs/publicacoes/GUIA_FONTES_E_CATALOGOS.pdf Acesso em: 9 fev. 2020; COSTA, Bruna Martins. Aprisionamento da loucura: internamento, psiquiatrização e controle penal. 2017. Monografia (Bacharelado em Direito) - Universidade Federal de Santa Catarina, Florianópolis, 2017.

39 O aumento do encarceramento no Brasil se deve ao aumento da repressão ao tráfico de drogas, tratado pela legislação especial penal como crime hediondo, diante do foco da polícia à persecução em periferias e favelas, onde se localiza o mercado ilícito do varejo de drogas. BOITEUX, Luciana. Drogas e cárcere: repressão às drogas, aumento da população penitenciária brasileira e alternativas. In: SHECAIRA, Sérgio Salomão. Drogas: uma nova perspectiva. São Paulo: IBCCRIM, 2014. p. 83-103. No Rio de Janeiro, essa política criminal é bastante evidente. Os fatores que podem ter influenciado essa queda de institucionalização experimentado no estado fluminense têm natureza política, econômica e social. Qualquer análise sobre esses números dificilmente dará conta de identificar todos os elementos por trás desse processo.

40 A desisntitucionalização é um trabalho de transformação que, partindo do manicômio, desmonta a solução institucional existente para, sem seguida, desconstruir o problema. O resultado de tal prática transforma os mecanismos de tratamento e as concepções de sofrimento, tendo em vista que o tratamento, a terapia, deixa de ser mera busca pela cura da doença, dando lugar a um processo complexo, cotidiano e crítico. ROTELLI, Franco. Desinstitucionalização. São Paulo: Hucitec/Edusp, 1990.

${ }_{41}$ MAGNO, Patrícia Carlos. Encarceramento feminino: um olhar sobre mulheres e medida de segurança. In: BERNER, Vanessa Batista; JUCÁ, Roberta Laena Costa; MORAES, Heloisa Melino (org.). Teoria crítica, descolonialidade e direitos bumanos. Rio de Janeiro: Freitas Bastos, 2016. p. 115-155. p. 120. 
ruptura com o modelo hospitalocêntrico, uma vez que é marcada pelo tratamento em meio aberto, pensado de forma individualizada para cada usuário, territorializado, e que valoriza a integração com a família e a sociedade. Um outro olhar para a loucura, voltado para o sujeito e não para a doença, passa a ser valorizado. Essa virada possibilita, assim, que o foco deixe de ser a repressão e a segurança pública, e passe a ser a saúde.

Apesar do avanço no campo legislativo provocado pela referida lei, pelo Estatuto da Pessoa com Deficiência (Lei n. 13.146/2015), bem como por uma série de outras normativas nacionais e recomendações internacionais, na prática jurídica cotidiana verifica-se a inobservância das orientações firmadas por estes textos. A resistência à incorporação dessas diretrizes, especialmente no campo penal, consta como um dos principais entraves a serem contornados no curso da implementação do EMPAP.

É fato que a reflexão sobre o controle social formal-penal da loucura não foi amadurecida pelo discurso da reforma psiquiátrica, pela doutrina jurídica, ou pela consciência social. A própria Lei n. 10.216/2001 reflete essa realidade, uma vez que não abarca, explicitamente, a questão dos manicômios judiciários, nem enfrenta abertamente a relação da loucura com o sistema penal.

Existe, portanto, uma extensa discussão doutrinária sobre o suposto conflito entre a Lei da Reforma Psiquiátrica e a LEP, em relação ao fato de a primeira ter derrogado os dispositivos que regem o processo de execução da medida de segurança de internação. Alguns autores entendem que a Lei n. 10.216/2001 se aplica aos sujeitos em sofrimento mental em conflito com a lei, pois seu texto não estabelece qualquer exceção à aplicação dos seus princípios gerais, inexistindo qualquer suporte constitucional para promover tal discriminação.

Por outro lado, há o argumento de que o referido diploma legal não altera explicitamente a Lei de Execução Penal, levando a um conflito aparente de normas no tempo. Jacobina reconhece que essa seria uma discussão de formalidades: por tratar de matéria de técnica legislativa, a Lei Complementar não obriga o intérprete e o operador da lei, mas o seu redator ${ }^{42}$.

A regra de hermenêutica a ser utilizada é a Lei de Introdução ao Código Civil do qual se depreende que a incompatibilidade lógica da lei anterior com a lei posterior implica revogação, ainda que não haja cláusula expressa nesse sentido. Apesar da sólida construção, a modificação parcial da LEP em matéria de medida de segurança não se firmou e as medidas de internação seguem sendo equivocadamente aplicadas e executadas ${ }^{43}$.

Para além desse entrave jurídico-formal, outra grande dificuldade reside no fato de ser necessária a superação da lógica manicomial, que extravasa o espaço físico da instituição total, permeia o imaginário social e é reproduzida pelo senso comum. A Carta de Bauru ${ }^{44}$, documento fundador do Movimento Nacional da Luta Antimanicomial (MNLA), informa que o manicômio é a expressão de uma estrutura opressora da sociedade e que, portanto, a luta pelos direitos das pessoas com transtornos mentais deve acontecer concomitante e conjuntamente à luta de todos os trabalhadores pelo acesso à saúde, à justiça e a melhores condições de vida.

Buscar a concretização de uma sociedade sem manicômios significa combater a exclusão e a discriminação, garantindo que todas as pessoas com transtornos mentais tenham acesso ao tratamento em saúde mental, independentemente de terem sido ou não alvo do controle formal-penal. A ressignificação da execução da medida de segurança passa por estratégias de retirada dos sujeitos em sofrimento psíquico da mira do controle médico-psiquiátrico e formal-penal, direcionando seu cuidado para o campo da saúde, da assistência social, da educação e das artes.

Em conformidade com essa orientação, o Ministério Público Federal, por meio da Procuradoria Federal dos Direitos do Cidadão (MPF/PFDC), elaborou um parecer acerca das medidas de segurança, recomen-

42 JACOBINA, Paulo Vasconcelos. Direito penal da loucura: medida de segurança e reforma psiquiátrica. Brasília: ESMPU, 2008. p. 104. 43 JACOBINA, Paulo Vasconcelos. Direito penal da loucura: medida de segurança e reforma psiquiátrica. Brasília: ESMPU, 2008.

44 CONSELHO FEDERAL DE PSICOLOGIA. Carta de Bauru, 2017. Disponível em: https://site.cfp.org.br/wp-content/uploads/2017/12/CARTA-DE-BAURU-30-ANOS.pdf. Acesso em: 9 fev. 2020. 
dando o afastamento de diversos dispositivos do Código Penal, Código de Processo Penal e da Lei de Execução Penal ${ }^{45}$. Os pontos contestados nestas leis foram especialmente aqueles que endossam o atributo da periculosidade. Ainda que a natureza conceitual do termo seja bastante imprecisa, parece haver uma convergência no sentido de tratá-lo como sendo um dispositivo de poder e controle de indivíduos, constantemente disputado pelos saberes penal e psiquiátrico.

Diniz, reforçando a fragilidade do conceito, ainda constata que inexiste nexo de causalidade entre diagnóstico psiquiátrico e infração penal ${ }^{46}$. Isso porque, no censo de 2011 , por ela coordenado, verificou-se que as mesmas infrações penais foram praticadas por indivíduos com diagnósticos psiquiátricos distintos.

Exames psiquiátricos, como o incidente de insanidade menta $1^{47}$, no curso do processo penal, e o exame de verificação de cessação de periculosidade, para avaliar o paciente no momento de sua potencial desinternação, sintetizam a associação entre o poder psiquiátrico e o poder penal. Com base nessa compreensão, e considerando-se a importância da construção de novas políticas para as pessoas em sofrimento psíquico em conflito com a lei, a DPERJ rompeu com parte dessa lógica.

No Rio de Janeiro, em substituição ao EVCP, passou a vigorar o EMPAP. Antimanicomial em essência, foi elaborado tendo como inspiração vários projetos e práticas exitosas tanto no Brasil quanto no exterior. Magno e Boiteux pensam o novo instrumento a partir de uma metodologia que tem o direito como ferramenta garantidora de lutas e interesses sociais, e veem a Defensoria Pública como órgão vocalizador de demandas emancipatórias de pessoas em situação de vulnerabilidade. Esse projeto busca combater, na prática, a "discriminação interseccional estrutural, traduzida no conceito/mito da periculosidade do/a louco/a"48, que é inclusive produzida e reforçada pelo próprio sistema de justiça.

O EMPAP é, portanto, produto do uso contra-hegemônico do direito, implicado em provocar fissuras internas ao sistema. Sua construção, além de contribuir teoricamente para os debates críticos dos direitos humanos e da criminologia, também propõe uma política pública penitenciária e de saúde, pautada no desencarceramento e, mais amplamente, na desinstitucionalização do paciente ${ }^{49}$.

Um dos elementos diferenciadores do plano é a implementação de um projeto terapêutico singular (PTS), que é definido pelo Ministério da Saúde ${ }^{50}$ como "instrumento de organização do cuidado em saúde construído entre equipe e usuário, considerando as singularidades do sujeito e a complexidade de cada caso".

No PTS, a identificação das necessidades de saúde, a discussão do diagnóstico e a definição do cuidado são compartilhadas, o que leva ao aumento da eficácia dos tratamentos, uma vez que a ampliação da comunicação fortalece vínculos e aumenta o grau de corresponsabilização. Ele se constitui, portanto, como um conjunto de propostas terapêuticas articuladas, resultantes da discussão entre uma equipe interdisciplinar.

A utilização do PTS como dispositivo de intervenção desafia a organização tradicional do trabalho em

\footnotetext{
45 BRASIL. Ministério Público Federal. Procuradoria Federal dos Direitos do Cidadão. Parecer sobre medidas de segurança e hospitais de custódia e tratamento psiquiátrico sob a perspectiva da Lei n. 10. 216/2001, 2011. Disponível em: http://pfdc.pgr.mpf.mp.br/temas-deatuacao/saude-mental/docs-publicacoes/parecer_medidas_seguranca_web.pdf. Acesso em: 29 maio 2020.

46 DINIZ, Débora. A custódia e o tratamento psiquiátrico no Brasil: Censo 2011. Brasília: Letras Livres, 2013.

47 O mecanismo de averiguação da periculosidade, que identifica o sujeito como inimputável, durante a instrução processual, é o incidente de insanidade mental, que possui como principal subsídio a perícia psiquiátrica. CARVALHO, Salo de; WEIGERT, Mariana de Assis Brasil e. Sofrimento e clausura no Brasil contemporâneo: estudos críticos sobre fundamentos e alternativas às penas e medidas de segurança. Florianópolis: Empório do Direito, 2017.

48 MAGNO, Patrícia Carlos.; BOITEUX, Luciana. Quando a luta antimanicomial mira no manicômio judiciário e produz desencarceramento: uma análise dos arranjos institucionais provocados pela defensoria pública no campo da política pública penitenciária e de saúde mental. Revista Brasileira de Políticas Públicas, Brasília, v. 8, n. 1, p. 574-604, 2018. p. 578.

49 MAGNO, Patrícia Carlos.; BOITEUX, Luciana. Quando a luta antimanicomial mira no manicômio judiciário e produz desencarceramento: uma análise dos arranjos institucionais provocados pela defensoria pública no campo da política pública penitenciária e de saúde mental. Revista Brasileira de Políticas Públicas, Brasília, v. 8, n. 1, p. 574-604, 2018. p. 579.

50 BRASIL. Ministério da Saúde. Núcleo de Apoio de Saúde da Família - Volume 1: ferramenta para a gestão e o trabalho cotidiano, 2014. Disponível em: http://bvsms.saude.gov.br/bvs/publicacoes/nucleo_apoio_saude_familia_cab39.pdf. Acesso em: 9 fev. 2020.
} 
saúde, pois pressupõe a necessidade de maior articulação entre os profissionais, e a utilização das reuniões de equipe e de outros espaços coletivos como locais de reflexão, compartilhamento, discussão e corresponsabilização das ações, bem como a horizontalização de poderes e conhecimentos. Ele é um projeto mutável, que se (re)formula cotidianamente ${ }^{51}$.

Dentro do EMPAP, ele é elaborado pela equipe de saúde do ECTP, que é responsável pela assistência durante a internação e pela articulação com a RAPS do território dos pacientes. Nele há os mecanismos de desinstitucionalização, que constarão no processo. O perito do EMPAP deixa, portanto, o prédio físico do Instituto de Perícias e passa a periciar o corpo do desinternado no chão do manicômio ${ }^{52}$. Esse profissional não mais indica se o sujeito é ou não perigoso, como se a loucura fosse um defeito inerente, mas sim se a pessoa com transtornos mentais tem ou não condição clínica de ser desinternada e continuar o tratamento em meio comunitário, conforme os ditames da Lei n. 10.216/2001.

$\mathrm{O}$ atendimento jurídico funciona como suporte à construção do projeto terapêutico singular e à apresentação de estratégias de desinternação e desospitalização para o sistema de justiça, garantindo que o futuro egresso possa ser acolhido pelos equipamentos de saúde extra-hospitalares e comunitários. É por meio da apropriação, pelo direito, da concepção de território da RAPS, que se desdobram planos que buscam viabilizar o deslocamento do controle formal-penal para o controle social comunitário da atenção psicossocial, e o enfrentamento do mito da periculosidade.

\section{Quem são as mulheres sujeitas à medida de segurança no Rio de Janeiro?}

Os primeiros casos para os quais foram produzidos o EMPAP no Rio de Janeiro totalizaram 25. Foram realizados a partir de agosto de 2017, e resultaram em desinternações entre outubro do mesmo ano e janeiro de 2018. Dentre estes, houve, apenas, um caso de transinstitucionalização, cuja paciente envolvida foi uma mulher — negra, pobre, periférica —, que foi desinternada do HPP RM e institucionalizada em um hospital psiquiátrico.

Transinstitucionalização é o processo pelo qual uma pessoa é deslocada de uma instituição total para outra, com a manutenção das características asilares. Inicialmente, foi tida como um recurso para viabilizar a desinstitucionalização de pacientes psiquiátricos, pois pretendia a transferência para hospitais em maior conformidade com as diretrizes da reforma psiquiátrica brasileira $(\mathrm{RPB})^{53}$.

Entretanto, ela passou a salientar novas internações de longa duração, promovendo o oposto da desinstitucionalização. Ainda que o uso costumeiro da transinstitucionalização esteja associado à troca de uma instituição psiquiátrica por outra, pensamos que o termo pode ser utilizado de modo a abranger o deslocamento de pessoas entre instituições totais distintas ${ }^{54}$, uma vez que se preservam as características determinantes

\footnotetext{
51 MAGNO, Patrícia Carlos.; BOITEUX, Luciana. Quando a luta antimanicomial mira no manicômio judiciário e produz desencarceramento: uma análise dos arranjos institucionais provocados pela defensoria pública no campo da política pública penitenciária e de saúde mental. Revista Brasileira de Políticas Públicas, Brasília, v. 8, n. 1, p. 574-604, 2018.

52 MAGNO, Patrícia Carlos.; BOITEUX, Luciana. Quando a luta antimanicomial mira no manicômio judiciário e produz desencarceramento: uma análise dos arranjos institucionais provocados pela defensoria pública no campo da política pública penitenciária e de saúde mental. Revista Brasileira de Políticas Públicas, Brasília, v. 8, n. 1, p. 574-604, 2018.

53 LHACER, Patrícia Maria Villa. Transinstitucionalização: caminhos e descaminhos na dinâmica de internações e desinternações de pessoas com transtorno mental em conflito com a lei no estado de São Paulo. 2019. Tese (Doutorado em Saúde Pública) - Programa de Pós-Graduação em Saúde Pública, Universidade de São Paulo, São Paulo, 2019.

54 As instituições totais podem ser organizadas em cinco grupos. No primeiro estão as instituições criadas para cuidar de pessoas que, em princípio, são incapazes e inofensivas (casas de idosos, órfãos, indigentes). No segundo, estão os locais destinados a pessoas incapazes de cuidar de si mesmas e que são uma ameaça para a comunidade, embora de maneira não intencional (sanatórios, manicômios, hospitais). O terceiro grupo é organizado para proteger a comunidade contra perigos intencionais (cadeias, penitenciárias,
} 
desses locais.

Conforme revelam os dados levantados por Diniz ${ }^{55}$, Magno e Boiteux ${ }^{56}$, o Departamento Penitenciário Nacional (DEPEN), utilizando informações fornecidas pelo governo estadual, publicou, erroneamente, que inexistiam mulheres cumprindo medida de segurança no estado do Rio de Janeiro ${ }^{57}$. Uma análise interseccional dos dados colhidos por essas pesquisadoras e por Ramos ${ }^{58}$ mostra que as mulheres definidas como loucas e submetidas à medida de segurança são mais brancas do que as demais mulheres privadas de liberdade no estado.

Esses dados dão margem para questionarmos em que medida mulheres brancas podem se "beneficiar" da loucura e utilizá-la como recurso para escapar da prisão comum. Por outro lado, esta não responsabilização penal é mais difícil de se sustentar no caso das mulheres negras. Apesar de nós, pesquisadoras da área, termos conhecimento sobre a maior invisibilização das mulheres em sofrimento psíquico em conflito com a lei, para o senso comum ainda é pior estar presa do que estar em tratamento médico. Essa inferência demonstra que, no imaginário popular, as mulheres brancas seriam recuperáveis, enquanto as negras não, restando-lhes, apenas, a segregação ${ }^{59}$.

Além disso, os crimes contra a vida aparecem como sendo o tipo penal de maior incidência entre as pessoas — inclusive as mulheres — "loucas", sem que haja um nexo causal entre periculosidade inerente e diagnósticos psiquiátricos. Tendo em vista que as pessoas com transtornos mentais estão mais adstritas ao ambiente doméstico, ao âmbito privado, é de se esperar que a maioria das condutas ocorra neste locus ou em suas adjacências - a vižinhança ${ }^{60}$.

Outra questão fundamental que permeia o debate sobre medidas de segurança é o tempo de internação. Uma das críticas mais severas ao instituto diz respeito ao fato de que, apesar de estabelecer um tempo mínimo, a legislação penal não prevê um tempo máximo de internação ${ }^{61}$, e exige um laudo psiquiátrico para que seja auferida a cessação da periculosidade do paciente.

Pela literatura consultada, é possível afirmar que as mulheres ficam mais tempo internadas que os homens $^{62}$. Apesar disso, não é possível estabelecer uma relação direta entre o tempo de internação e a gravida-

campos de concentração). O quarto modelo são aquelas instituições estabelecidas para realizar tarefas de trabalho (quartéis, escolas internas, campos de trabalho). No quinto estão os estabelecimentos destinados ao refúgio do mundo (mosteiros, conventos). Entretanto, esta classificação não é exaustiva e não tem uso analítico imediato. Ela fornece definições que, associadas a outras, podem ser instrumentalizadas e utilizadas como ponto de partida. GOFFMAN, Erving. Manicômios, prisões e conventos. São Paulo: Perspectiva, 1974.

55 DINIZ, Débora. A Custódia e o Tratamento Psiquiátrico no Brasil: Censo 2011. Brasília: Letras Livres, 2013.

56 MAGNO, Patrícia Carlos.; BOITEUX, Luciana. Quando a luta antimanicomial mira no manicômio judiciário e produz desencarceramento: uma análise dos arranjos institucionais provocados pela defensoria pública no campo da política pública penitenciária e de saúde mental. Revista Brasileira de Políticas Públicas, Brasília, v. 8, n. 1, p. 574-604, 2018.

57 BRASIL. Ministério da Justiça. Levantamento Nacional de Informações Penitenciárias - INFOPEN Mulheres, 2014. Disponível em: https://www.justica.gov.br/news/estudo-traca-perfil-da-populacao-penitenciaria-feminina-no-brasil/relatorio-infopen-mulheres. pdf. Acesso em: 9 fev. 2020.

58 RAMOS, Bruna Gabriela Monte de Oliveira. Compreendendo atravessamentos de gênero, raça/ etnia, e classe no processo de desisntitucionalização das mulheres em sofrimento psíquico em conflito com a lei no estado do Rio de Janeiro. 2018. Dissertação (Mestrado em Psicologia) - Programa de Pós-Graduação em Psicologia, Universidade Federal do Rio Grande do Fluminense, Niterói, 2018.

59 De qualquer forma, mais pesquisas são necessárias para sustentar essas considerações enquanto hipótese plausível.

${ }^{60}$ São necessárias outras investigações mais aprofundadas para melhor estudar o fenômeno e confirmar essa hipótese.

${ }^{61}$ CARVALHO, Salo de; WEIGERT, Mariana de Assis Brasil e. Sofrimento e clausura no Brasil contemporâneo: estudos críticos sobre fundamentos e alternativas às penas e medidas de segurança. Florianópolis: Empório do Direito, 2017.

62 MAGNO, Patrícia Carlos. Encarceramento feminino: um olhar sobre mulheres e medida de segurança. In: BERNER, Vanessa Batista; JUCÁ, Roberta Laena Costa; MORAES, Heloisa Melino (org.). Teoria crítica, descolonialidade e direitos bumanos. Rio de Janeiro: Freitas Bastos, 2016. p. 115-155; MAGNO, Patrícia Carlos.; BOITEUX, Luciana. Quando a luta antimanicomial mira no manicômio judiciário e produz desencarceramento: uma análise dos arranjos institucionais provocados pela defensoria pública no campo da política pública penitenciária e de saúde mental. Revista Brasileira de Políticas Públicas, Brasília, v. 8, n. 1, p. 574-604, 2018; RAMOS, Bruna Gabriela Monte de Oliveira. Compreendendo atravessamentos de gênero, raşal etnia, e classe no processo de desisntitucionalização das mulheres em sofrimento psíquico em conflito com a lei no estado do Rio de Janeiro. 2018. Dissertação (Mestrado em Psicologia) - Programa de PósGraduação em Psicologia, Universidade Federal do Rio Grande do Fluminense, Niterói, 2018. 
de do fato praticado. A respeito do contexto de implementação do EMPAP, verificou-se que a articulação entre sistema de justiça e RAPS bem como a potência do PTS influenciam o tempo de internação.

Magno e Boiteux partem de uma compreensão de que as mudanças paradigmáticas se fazem por substituição. O EMPAP representa um substitutivo do EVCP, e, por meio desse novo instrumento, a lógica antimanicomial, materializada na atenção psicossocial, suprimiria a lógica do positivismo criminológico. Para concretizar essa política no âmbito do processo penal, foram necessários diversos rearranjos institucionais, sendo o principal deles a articulação entre sistema de saúde e de assistência social, e sistema de justiça ${ }^{63}$.

\section{Do ETCP ao hospital psiquiátrico: a atuação dos mecanismos de controle social formal e informal sobre as mulheres egressas da medida de segurança de internação}

Nesse momento, com o objetivo de ilustrar o caminho teórico-analítico percorrido e de demonstrar a atuação dos mecanismos de controle social, especialmente formal-penal, sobre as mulheres egressas da medida de segurança de internação, analisaremos alguns aspectos emblemáticos do caso ${ }^{64}$ de transinstitucionalização de uma ex-paciente do HPP RM.

A respeito dos 25 pacientes que foram contemplados pelo EMPAP no primeiro biênio após sua implementação, apenas um deles não foi desinstitucionalizada. Trata-se, na verdade, de uma paciente, negra, pobre, periférica, solitária, que, após ter sido considerada apta para a desinternação da medida de segurança, não foi desospitalizada e sofreu um processo de transintitucionalização.

Ao prestigiarmos uma metodologia pautada no diálogo contínuo e constante entre a literatura e o caso concreto, elegemos alguns fatos e acontecimentos que retratam de forma emblemática a atuação dos mecanismos de controle social, especialmente do controle formal-penal, mesmo após a saída da paciente do ECTP em virtude de sua desinternação.

É possível afirmar que existe uma associação entre as rupturas com um ideal hegemônico feminino e a criminalização de mulheres. A profissão, a classe social, a mobilidade no espaço público, dentre outros elementos, são importantes indicadores da estigmatização de determinados estereótipos considerados mais propensos à prática de condutas criminosas ${ }^{65}$.

Esse mapeamento também permite afirmar que no caso das mulheres a distinção entre um mero desvio e um crime é extremamente volátil, e está muito mais sujeita às ingerências e às diretrizes do controle social informal. A interferência do controle penal não impede que esses mecanismos continuem funcionando, mas apenas adiciona uma forma de coerção respaldada por forças institucionais e, teoricamente, mais estruturadas e sistematizadas.

Identificamos que, em um determinado momento, o controle social informal não foi suficiente para coibir o desvio, a transgressão, o não cumprimento do ideal hegemônico feminino, fazendo-se necessária a intervenção do controle social formal-penal. Essa insuficiência, como vimos, pode ser motivada por circunstâncias e condições bastante heterogêneas.

\footnotetext{
63 MAGNO, Patrícia Carlos.; BOITEUX, Luciana. Quando a luta antimanicomial mira no manicômio judiciário e produz desencarceramento: uma análise dos arranjos institucionais provocados pela defensoria pública no campo da política pública penitenciária e de saúde mental. Revista Brasileira de Políticas Públicas, Brasília, v. 8, n. 1, p. 574-604, 2018.

${ }_{64}$ Na pesquisa original, utilizou-se a metodologia do estudo de caso, com suporte na análise documental. Neste artigo, limitamonos a trazer as reflexões mais imediatamente relacionadas à atuação dos mecanismos de controle social formal-penal sobre as mulheres com sofrimento psíquico e mental que estiveram submetidas à medida de segurança de internação.

65 ANGOTTI, Bruna. Entre as Leis da Ciência, do Estado e de Deus: o surgimento dos presídios femininos no Brasil. 2. ed. San Miguel de Tucumán: Universidad Nacional de Tucumán; Instituto de Investigaciones Históricas Leoni Pinto, 2018. p. 90.
} 
Acreditamos que dois são os aspectos mais emblemáticos passíveis de serem extraídos do caso eleito para ser utilizado de forma ilustrativa. Um primeiro registro da incidência dos mecanismos de controle social sobre as mulheres em sofrimento psíquico em conflito com a lei diz respeito ao comportamento antissocial, antijurídico e ilícito das egressas. Ou seja, está relacionado ao desvio do ideal hegemônico feminino.

No caso concreto, a conduta da paciente transinstitucionalizada foi enquadrada como homicídio tentado contra sua vizinha, e não como lesão corporal. Como consequência, o processo transcorreu na Vara do Tribunal do Júri, e não na Vara Criminal comum. Apesar de não ter tido acesso ao processo penal e desconhecer detalhes mais minuciosos sobre o conflito, parece-nos um exemplo do fenômeno já identificado por Magno $^{66}$, que observou um tratamento mais gravoso em sede de decisão judicial às condutas praticadas por mulheres "loucas".

Um segundo aspecto está ligado aos saberes-poderes jus e psi. No caso das mulheres egressas da medida de segurança, a atuação do controle formal-penal deveria "oficialmente" cessar com sua desinternação. Tomando de forma ilustrativa o caso da única paciente transinstitucionalizada, apesar de toda a construção conjunta, multiprofissional, pautada no PTS, prestigiada e estimulada pelo EMPAP dentro da instituição, os mecanismos de controle social formal mantiveram sua atuação, tendo em vista que coube ao direito a última palavra sobre a regulação das estratégias e diretrizes da desinstitucionalização.

É inerente à medida de segurança a ação simultânea e concomitante do controle social formal-penal e do médico-psiquiátrico. Esse casamento é sustentado, por um lado, pelas instituições totais ${ }^{67}$, e, por outro, pela psiquiatria — na verdade, pela a união dos saberes $p s i^{68}$ - forense, um terceiro saber-poder ${ }^{69}$ muito mais atrelado à moral do que à ciência. Pode-se dizer que na transinstitucionalização houve, apenas, o deslocamento de algumas atribuições do controle social formal-penal para o médico-psiquiátrico, o que não seria suficiente para desmobilizar uma atuação simultânea de ambos, se necessário.

Entretanto, ficou evidente que o saber-poder dominante era o jurídico, que possui instrumentos para se manter acima dos outros e para exigir-lhes subsunção. Esse fenômeno pôde ser observado, principalmente, em dois momentos. No primeiro deles, a DPERJ exigiu informações sobre o acolhimento da paciente no hospital psiquiátrico, para saber se estava sendo dada continuidade ao processo de desinstitucionalização iniciado com o EMPAP. Nesse caso, o órgão agiu como garantidor de direitos e visando à concretização de uma política pública antimanicomial.

Em uma segunda ocasião, já havia uma decisão favorável à desinstitucionalização, na qual as saídas desacompanhadas da paciente deviam ser subentendidas em virtude da própria natureza do conceito. Além disso, se houvesse o descumprimento dos acordos estabelecidos no processo, seria ela quem responderia autonomamente perante o sistema de justiça.

Apesar disso, a equipe multidisciplinar responsável comunicou à juíza da Vara de Execuções Penais sobre as saídas e mencionaram ser este um meio de terem um respaldo para caso algo ocorresse. Além da preocupação existente em relação à paciente, ficou evidente a tensão em relação a uma futura responsabilização jurídica dos profissionais da equipe.

Ainda que cessada a medida de segurança de internação, o estigma de anormal e desviante não se dissipará tão facilmente. Mesmo no caso das ex-pacientes colocadas em liberdade, é possível deduzir, recuperando as reflexões propostas ao longo deste artigo, que o controle social não cessou sua atuação sobre seus corpos

\footnotetext{
${ }_{66}$ MAGNO, Patrícia Carlos. Encarceramento feminino: um olhar sobre mulheres e medida de segurança. In: BERNER, Vanessa Batista; JUCÁ, Roberta Laena Costa; MORAES, Heloisa Melino (org.). Teoria crítica, descolonialidade e direitos bumanos. Rio de Janeiro: Freitas Bastos, 2016. p. 115-155.

67 GOFFMAN, Erving. Manicômios, prisões e conventos. São Paulo: Perspectiva, 1974.

68 ANDRADE, Ana Paula Müller de. (Entre)laçamentos possíveis entre gênero e saúde mental. In: ZANELLO, Valeska; ANDRADE, Ana Paula Müller de. (org.). Saúde mental e gênero: diálogos, práticas e interdisciplinaridade. Curitiba: Appris, 2014. p. $59-77$.

69 FOUCAULT, Michel. Os anormais: curso no Collège de France (1975-1976). 3. ed. São Paulo: Martins Fontes, 2001.
} 
e psiquês. A intensidade desse rótulo e do controle sobre as mulheres pode ser ilustrada pelo fato de que a única pessoa que, após ter decretada a desinternação, passou por uma transintitucionalização, foi uma mulher, negra, pobre e periférica.

Existe uma série de fatores que influenciaram nessa trajetória, mas pensamos que reforçar esta provocação é pertinente e merece algumas reflexões. Consta nos documentos que a transinstitucionlização ajudaria a reorganização da vida da paciente, uma vez que ela não possuía família ou amigos. Isso se confirmou em certa medida: ela havia avançado significativamente nos estudos, apresentava um quadro psíquico estável e tinha conseguido obter uma renda fixa para viver assim que deixasse a instituição psiquiátrica. Por outro lado, sua permanência nesta instituição limitou significativamente sua autonomia.

Ao contrário do que objetiva o EMPAP, não ficou nítida uma mudança do controle social formal-penal para o controle psicossocial comunitário. Pareceu-nos que houve, apenas, o deslocamento parcial de certas atribuições para o controle médico-psiquiátrico. O caso em questão foi marcado por uma "etapa intermediária" dentro do processo de desinstitucionalização, caracterizada pela transinstitucionalização. Pensamos que essa zona nebulosa, cujo alcance das políticas substitutivas é exíguo, foi a principal explicação para manter a paciente institucionalizada. Essa etapa intermediária é, portanto, facilmente justificável se levantadas as possibilidades materiais disponíveis na ocasião.

Por sua vez, essa constatação não apaga o fato de que a paciente em questão não possuía familiares e/ ou amigos. Para as mulheres negras, especialmente em situação de privação de liberdade, o abandono é uma realidade e a solidão deve ser tratada como resultado de uma estrutura racista e sexista ${ }^{70}$, pois frequentemente é uma imposição e não uma escolha.

Entendemos que, diante da realidade da paciente, poucas opções pareciam viáveis. Tratava-se de um processo extremamente complexo, que envolvia o balizamento das políticas universalistas do SUS e as demandas singulares dos sujeitos em sofrimento psíquico. Se, por um lado, ficou demonstrado que a paciente transinstitucionalizada continuou sob alvo dos controles formal-penal e médico psiquiátrico, por outro, não há como garantir que as outras egressas desinstitucionalizadas passaram a desfrutar do controle psicossocial comunitário. Apesar dos esforços do EMPAP, o exemplo em questão mostra como as conquistas da reforma psiquiátrica brasileira são frágeis e insuficientes se não acompanhadas de mudanças econômicas, sociais e culturais mais consistentes.

O caso concreto trouxe à tona o caráter estrutural da permanente incapacidade de as políticas públicas em saúde mental alcançarem a todos. Para além de chamar a atenção para a necessidade de ampliação da RAPS e de aumento no investimento em serviços substitutivos, o caso ilustra que a produção do sofrimento não é algo meramente conjuntural e está diretamente relacionada à estrutura social capitalista, racista, machista, normatizadora e normalizadora.

\section{Considerações finais}

Ao nos questionarmos sobre como age o controle formal-penal sobre as mulheres egressas da medida de segurança de internação no Rio de Janeiro, procuramos entender de que forma o ideal hegemônico feminino, erigido como parâmetro de normalidade das mulheres, autoriza que sujeitas que não o satisfazem possam ser permanentemente subjugadas, oprimidas, excluídas e punidas.

Os processos de subjetivação de homens e mulheres, de pessoas negras e brancas, de pessoas "loucas"

70 GONZALES, Lélia. Racismo e sexismo na cultura brasileira. Ciências Sociais Hoje, São Paulo, p. 223-344, 1984; PACHECO, Ana Cláudia Lemos. Raça, gênero e escolhas afetivas: uma abordagem preliminar sobre a solidão entre mulheres negras na Bahia. Revista dos Pós-Graduandos em Ciências Sociais, Campinas, n. 21/22, p. 11-48, 2003. 
não são os mesmos, e criam vulnerabilidades identitárias específicas e diferenciadas, evidenciadas no sofrimento psíquico. A opção pela adoção de uma lente interseccional, descolonial e antimanicomial é um importante recurso teórico-metodológico para contemplar as mulheres negras, indígenas, lésbicas, loucas, terceiro-mundistas.

As formas de controle social que incidiam, e incidem, sobre as mulheres eram tanto de natureza informal, exercidas pela família, opinião pública, trabalho, escola, igreja, medicina, quanto formal, colocadas em prática pelos órgãos estatais. Apesar de apresentarem suas próprias dinâmicas de funcionamento, é comum que esses mecanismos de controle ajam simultaneamente e em conjunto.

A incapacidade de dar conta dos papéis atribuídos às mulheres pelo ideal feminino hegemônico branco é percebida como desvio. Historicamente, a busca pela "anormalidade" se mostrou mais refinada e incisiva no caso das mulheres: a loucura feminina recebeu especial atenção da literatura médica e se constituiu de forma bastante própria.

A condenação das formas de vida de pessoas pobres e negras mostra, ainda, uma outra faceta do controle social, bem mais dura, que opera tanto de modo informal, sobre a mobilidade dos corpos negros, como de modo formal, a partir de forças institucionalizadas de repressão policial. As mulheres negras em momento algum satisfizeram o ideal hegemônico e estavam fadadas a integrar a categoria de desviante quando o controle social informal não era capaz de estabelecer limites, sendo possível criminalizá-las pelo desvio do ideal hegemônico feminino.

Sobre o saber psiquiátrico e sua inserção no campo forense, há um discurso especificamente direcionado para a loucura criminal, que é voltado para a normalização dos indivíduos, e não para a prevenção do crime ou para a cura da doença mental. O principal reflexo desse movimento da psiquiatria forense parece ter se concentrado nos exames psiquiátricos. Como requisito para a extinção da medida de segurança, atribuída às mulheres em sofrimento psíquico e mental em conflito com a lei, é necessária a realização do EVCP, cuja função da perícia psiquiátrica é demonstrar que o indivíduo já era potencialmente desviante antes mesmo de cometer qualquer ilícito.

Antimanicomial em essência, o EMPAP vem para substituir o EVCP, principal símbolo da herança periculosista e manicomial do positivismo criminológico e da psiquiatria tradicional. O novo instrumento tem o direito como ferramenta garantidora de lutas e interesses sociais, e busca combater a discriminação interseccional estrutural traduzida no mito da periculosidade do louco, que é, inclusive, produzido e reforçado pelo próprio sistema de justiça.

Analisando a construção de estereótipos femininos normais e desviantes, é possível identificar permanências significativas, tanto no senso comum quanto em práticas e abordagens consideradas inovadoras. A inclusão de uma perspectiva antimanicomial no referencial interseccional e descolonial de análise busca adicionar a crítica ao modelo asilar de "tratamento" e captura de uma parcela das mulheres consideradas desviantes.

Debruçamo-nos sobre a condição das ex-pacientes do Hospital Penal Psiquiátrico Roberto de Medeiros (HPP RM) que foram contempladas pelo EMPAP entre os anos de 2017 e 2018, o primeiro biênio após a implementação do projeto. Nosso objetivo era identificar como o mecanismo de controle formal-penal atua sobre as mulheres egressas da medida de segurança de internação no Rio de Janeiro e como outras formas passaram a agir.

Para tornar essas reflexões mais palpáveis, trouxemos o exemplo de uma egressa que não foi realmente desinstitucionalizada, mas transinstitucionalizada. Partimos desse caso para expor alguns elementos que identificamos como marcantes sobre o funcionamento dos mecanismos de controle social, especialmente do controle social formal-penal, sobre mulheres que foram estigmatizadas como "loucas criminosas".

Identificamos que os aspectos mais emblemáticos se ligam, principalmente, a dois debates. O primeiro 
diz respeito ao comportamento antissocial, antijurídico e ilícito das egressas, estando relacionado ao desvio do ideal hegemônico feminino. O segundo está relacionado à associação entre os saberes-poderes jus e psi.

No caso da medida de segurança, o controle social formal-penal e o médico-psiquiátrico agem concomitante e simultaneamente. Esse casamento é sustentado pelas instituições totais e pela união dos saberes jus e $p s i$, na composição da psiquiatria forense, como um terceiro discurso muito mais atrelado à moral do que à ciência. Ainda que esses campos respaldem e legitimem um ao outro, percebemos que no caso concreto da egressa do HPP RM que foi transinstitucionalizada, predominou o saber-poder jurídico, que possuía ferramentas legais para se manter acima dos outros saberes e para exigir-lhes subsunção.

O caso, trazido de maneira exemplificativa, ilustra que o controle social formal-penal está sempre à espreita, mesmo no caso das ex-pacientes já em liberdade, que também estão sujeitas à atuação de outras formas de controle social formal e informal. Essas mulheres carregam consigo o estigma do desvio, da anormalidade, e, ao menor sinal desses, serão novamente capturadas pelo sistema penal.

Apesar dos esforços do EMPAP, as conquistas da reforma psiquiátrica brasileira são frágeis e insuficientes se não acompanhadas de mudanças econômicas, sociais e culturais mais consistentes. $\mathrm{O}$ caso concreto trouxe à tona o caráter estrutural da permanente incapacidade de as políticas públicas em saúde mental alcançarem a todos. Para além de chamar a atenção para a necessidade de ampliação da RAPS e de aumento no investimento em serviços substitutivos, o caso ilustra que a produção do sofrimento não é algo meramente conjuntural e está diretamente relacionada à estrutura social capitalista, racista, machista, normatizadora e normalizadora.

Assim como um extenso caminho a ser percorrido no que diz respeito a novos olhares sobre a loucura, há um longo processo de desconstrução e transgressão do ideal hegemônico feminino, ainda hoje referência de normalidade para as mulheres.

Apesar das críticas apresentadas, enfatizamos a importância de que as estratégias de desinstitucionalização de mulheres em cumprimento de medida de segurança de internação sigam sendo pensadas de forma multidisciplinar, bem como adotem posturas interseccionais e antimanicomiais para lidar com as demandas próprias de cada grupo e com as vulnerabilidades provocadas por cada tipo de opressão.

\section{Referências}

AKOTIRENE, Carla. Interseccionalidade. São Paulo: Pólen, 2019.

ANDRADE, Ana Paula Müller de. (Entre)laçamentos possíveis entre gênero e saúde mental. In: ZANELLO, Valeska; ANDRADE, Ana Paula Müller de. (org.). Saúde mental e gênero: diálogos, práticas e interdisciplinaridade. Curitiba: Appris, 2014. p. 59-77.

ANDRADE, Vera Regina Pereira de. A ilusão da segurança jurídica: do controle da violência a violência do controle penal. Porto Alegre: Livraria do Advogado, 1997.

ANGOTTI, Bruna. Entre as Leis da Ciência, do Estado e de Deus: o surgimento dos presídios femininos no Brasil. 2. ed. San Miguel de Tucumán: Universidad Nacional de Tucumán; Instituto de Investigaciones Históricas Leoni Pinto, 2018.

BARATTA, Alessandro. Criminologia crítica e crítica do direito penal: introdução à sociologia do direito penal. 3. ed. Rio de Janeiro: Revan, 2002.

BERNER, Vanessa de Oliveira Batista. Teorias feministas: o direito como ferramenta de transformação social. In: BERTOLIN, Patrícia Tuma Martins; ANDRADE, Denise Almeida de; MACHADO, Monica Sapucaia (org.). Mulher, sociedade e vulnerabilidade. Erechim: Deviant, 2017. p. 29-46. 
BOITEUX, Luciana. Drogas e cárcere: repressão às drogas, aumento da população penitenciária brasileira e alternativas. In: SHECAIRA, Sérgio Salomão. Drogas: uma nova perspectiva. São Paulo: IBCCRIM, 2014. p. 83-103.

BORGES, Juliana. O que é encarceramento em massa? Belo Horizonte: Letramento, 2018.

BRASIL. Lei n. 10.216, de 6 de abril de 2001. Dispõe sobre a proteção e os direitos das pessoas portadoras de transtornos mentais e redireciona o modelo assistencial em saúde mental. Disponível em: http://www. planalto.gov.br/ccivil_03/leis/leis_2001/110216.htm. Acesso em: 9 fev. 2020.

BRASIL. Lei n. 12.403, de 4 de maio de 2011. Altera dispositivos do Decreto-Lei n. 3.689, de 3 de outubro de 1941 - Código de Processo Penal, relativos à prisão processual, fiança, liberdade provisória, demais medidas cautelares, e dá outras providências. Disponível em: http://www.planalto.gov.br/ccivil_03/_ato20112014/2011/lei/112403.htm. Acesso em: 9 fev. 2020.

BRASIL. Ministério da Justiça e Segurança Pública. Conselho Nacional de Política Criminal e Penitenciária. Exposição de motivos, 2019. Disponível em: http://depen.gov.br/DEPEN/cnpcp-divulga-de-consulta-publica-do-plano-nacional-de-politica-criminal-e-penitenciaria/PNPCP220919.pdf. Acesso em: 9 fev. 2020.

BRASIL. Ministério da Justiça e Segurança Pública. Levantamento Nacional de Informacões Penitenciárias - INFOPEN Mulheres, 2018. Disponível em: http://depen.gov.br/DEPEN/depen/sisdepen/infopen-mulheres/ infopenmulheres_arte_07-03-18.pdf. Acesso em: 9 fev. 2020.

BRASIL. Ministério da Justiça e Segurança Pública. Levantamento Nacional de Informações Penitenciárias - INFOPEN Mulheres, 2019. Disponível em: http://depen.gov.br/DEPEN/depen/sisdepen/infopen-mulheres/ copy_of_Infopenmulheresjunho2017.pdf. Acesso em: 19 mar. 2020.

BRASIL. Ministério da Justiça. Levantamento Nacional de Informações Penitenciárias - INFOPEN Mulheres, 2014. Disponível em: https://www.justica.gov.br/news/estudo-traca-perfil-da-populacao-penitenciaria-feminina-no-brasil/relatorio-infopen-mulheres.pdf. Acesso em: 9 fev. 2020.

BRASIL. Ministério da Justiça. Portaria Interministerial n. 210, de 16 de janeiro de 2014. Institui a Política Nacional de Atenção às Mulheres em Situação de Privação de Liberdade e Egressas do Sistema Prisional, e dá outras providências. Disponível em: http://www.lex.com.br/legis_25232895_PORTARIA_ INTERMINISTERIAL_N_210_DE_16_DE_JANEIRO_DE_2014.aspx. Acesso em: 9 fev. 2020.

BRASIL. Ministério da Saúde. Núcleo de Apoio de Saúde da Familia - Volume 1: ferramenta para a gestão e o trabalho cotidiano, 2014. Disponível em: http://bvsms.saude.gov.br/bvs/publicacoes/nucleo_apoio_saude_familia_cab39.pdf. Acesso em: 9 fev. 2020.

BRASIL. Ministério Público Federal. Procuradoria Federal dos Direitos do Cidadão. Parecer sobre medidas de segurança e hospitais de custódia e tratamento psiquiátrico sob a perspectiva da Lei n. 10. 216/2001, 2011. Disponível em: http://pfdc.pgr.mpf.mp.br/temas-de-atuacao/saude-mental/docs-publicacoes/parecer_medidas_seguranca_web.pdf. Acesso em: 29 maio 2020.

CARVALHO, Salo de; WEIGERT, Mariana de Assis Brasil e. Sofrimento e clausura no Brasil contemporaneo: estudos críticos sobre fundamentos e alternativas às penas e medidas de segurança. Florianópolis: Empório do Direito, 2017.

CASTRO-GÓMEZ, Santiago; GROSFOGUEL, Ramón. Prólogo: Giro decolonial, teoria crítica y pensamento heterárquico. In: CASTRO-GÓMEZ, Santiago; GROSFOGUEL, Ramón. (Comp.). El Giro Descolonial: reflexiones para uma diversidade epistémica más allá del capitalismo global. Bogotá: Siglo del Hombre Editores, 2007. p. 9-24.

COLLINS, Patricia Hill. Black feminist thought. New York: Routledge, 2009.

CONSELHO FEDERAL DE PSICOLOGIA. Carta de Bauru, 2017. Disponível em: https://site.cfp.org. br/wp-content/uploads/2017/12/CARTA-DE-BAURU-30-ANOS.pdf. Acesso em: 9 fev. 2020. 
COSTA, Bruna Martins. Aprisionamento da loucura: internamento, psiquiatrização e controle penal. 2017. Monografia (Bacharelado em Direito) - Universidade Federal de Santa Catarina, Florianópolis, 2017.

COUTO, Rita Cristina Carvalho de Medeiros. Eugenia, loucura e condição feminina. Cadernos de Pesquisa, São Paulo, n. 90, p. 52-61, 1994.

DAVIS, Angela. Mulheres, raça e classe. São Paulo: Boitempo, 2016.

DINIZ, Débora. A custódia e o tratamento psiquiátrico no Brasil: Censo 2011. Brasília: Letras Livres, 2013.

FOUCAULT, Michel. Os anormais: curso no Collège de France (1975-1976). 3. ed. São Paulo: Martins Fontes, 2001.

FUNDAÇÃO OSWALDO CRUZ. Guia de fontes e catálogos de acervos e instituições para pesquisa em saúde mental e assistência psiquiátrica no estado do Rio de Janeiro. Rio de Janeiro: LAPS, 2004. Disponível em: http://bvsms. saude.gov.br/bvs/publicacoes/GUIA_FONTES_E_CATALOGOS.pdf Acesso em: 9 fev. 2020.

GOFFMAN, Erving. Manicômios, prisões e conventos. São Paulo: Perspectiva, 1974.

GONZALES, Lélia. Racismo e sexismo na cultura brasileira. Ciências Sociais Hoje, São Paulo, p. 223-344, 1984.

JACOBINA, Paulo Vasconcelos. Direito penal da loucura: medida de segurança e reforma psiquiátrica. Brasília: ESMPU, 2008.

LHACER, Patrícia Maria Villa. Transinstitucionalização: caminhos e descaminhos na dinâmica de internações e desinternações de pessoas com transtorno mental em conflito com a lei no estado de São Paulo. 2019. Tese (Doutorado em Saúde Pública) - Programa de Pós-Graduação em Saúde Pública, Universidade de São Paulo, São Paulo, 2019.

LUGONES, María. Colonialidad y género. Tabula Rasa, Bogotá, n. 9, p. 73-101, jul./dez., 2008.

MAGNO, Patrícia Carlos. Encarceramento feminino: um olhar sobre mulheres e medida de segurança. In: BERNER, Vanessa Batista; JUCÁ, Roberta Laena Costa; MORAES, Heloisa Melino (org.). Teoria crítica, descolonialidade e direitos humanos. Rio de Janeiro: Freitas Bastos, 2016. p. 115-155.

MAGNO, Patrícia Carlos.; BOITEUX, Luciana. Quando a luta antimanicomial mira no manicômio judiciário e produz desencarceramento: uma análise dos arranjos institucionais provocados pela defensoria pública no campo da política pública penitenciária e de saúde mental. Revista Brasileira de Políticas Públicas, Brasília, v. 8, n. 1, p. 574-604, 2018.

PACHECO, Ana Cláudia Lemos. Raça, gênero e escolhas afetivas: uma abordagem preliminar sobre a solidão entre mulheres negras na Bahia. Revista dos Pós-Graduandos em Ciências Sociais, Campinas, n. 21/22, p. 11-48, 2003.

PASSOS, Rachel Gouveia. Frantz Fanon, reforma psiquiátrica e luta antimanicomial no Brasil: o que escapou nesse processo? Sociedade em Debate, Pelotas, v. 25, n. 3, p. 74-88, set./dez., 2019.

PASSOS, Rachel Gouveia. "Holocausto ou navio negreiro?": inquietações para a Reforma Psiquiátrica Brasileira. Argum, Vitória, v. 10, n. 3, p. 10-22, set./dez., 2018.

RAMOS, Bruna Gabriela Monte de Oliveira. Compreendendo atravessamentos de gênero, raça/ etnia, e classe no processo de desisntitucionalização das mulheres em sofrimento psíquico em conflito com a lei no estado do Rio de Janeiro. 2018. Dissertação (Mestrado em Psicologia) - Programa de Pós-Graduação em Psicologia, Universidade Federal do Rio Grande do Fluminense, Niterói, 2018.

ROTELLI, Franco. Desinstitucionalização. São Paulo: Hucitec/Edusp, 1990.

ZANELLO, Valeska. Saúde mental, gênero e dispositivos: cultura e processos de subjetivação. Curitiba: Appris, 2018. 
Para publicar na revista Brasileira de Políticas Públicas, acesse o endereço eletrônico www.rbpp.uniceub.br

Observe as normas de publicação, para facilitar e agilizar o trabalho de edição. 